\title{
Promoção da Autonomia do Estudante: Experiência Vivenciada na Disciplina Estratégias e Instrumentos Educacionais para o Ensino de Ciências e Biologia (IB-USP)
}

\author{
Suzana Ursi*, Alessandra Fernandes Bizerra, Maria Aparecida Visconti \\ Departamentos de Botânica, Zoologia e Fisiologia do Instituto de Biociências da Universidade de São Paulo
}

* Autora para correspondência: suzanaursi@usp.br

\begin{abstract}
RESUMO
$\mathrm{O}$ presente relato tem como objetivo compartilhar as experiências vivenciadas na disciplina Estratégias e Instrumentos Educacionais para o Ensino de Ciências e Biologia (IB-USP), visando a promover maior interlocução sobre as práticas docentes no Ensino Superior, principalmente aquelas que almejam a autonomia do estudante de graduação. Foram adotadas estratégias buscando maior independência dos estudantes, culminando com uma proposta de cronograma aberto, na qual puderam escolher temáticas para desenvolver um projeto de elaboração-aplicação-avaliação de estratégias didáticas para o ensino de ciências, bem como opinar sobre os conteúdos a serem abordados na disciplina. Outro ponto de destaque refere-se às parcerias firmadas com diferentes espaços de Educação (formal e não formal), objetivando fortalecer o vínculo entre ensino e extensão na graduação. As ideias e ações adotadas na disciplina têm promovido maior autonomia dos estudantes, gerando motivação e entusiasmo.
\end{abstract}

Palavras-Chave: Autonomia; Estratégias Didáticas; Formação de Professores de Ciências; Ensino de Ciências.

\begin{abstract}
This report aims to share the experiences about the discipline Educational Strategies and Instruments for Science and Biology Teaching (IB-USP). We hope to improve the dialogue about Higher Education teaching, especially those that focus on the autonomy of undergraduate students. The strategies that we adopted increasingly seeking greater autonomy of students culminating with an open schedule proposal in which students could choose themes to develop a preparation-implementation-evaluation of design teaching strategies for science education. Additionally, they helped to choose the contents of the discipline. We highlight the importance of partnerships established with different education institutions (formal and non-formal education), which improved the relationship between teaching and extension on undergraduate degree. The discipline ideas and actions have promoted greater autonomy of students, creating motivation and enthusiasm.
\end{abstract}

Keywords: Autonomy; Educational Strategies; Science Teacher Training; Science Teaching.

\section{Introdução}

Atualmente, a simples aquisição de informações não pode mais ser encarada como suficiente para que os indivíduos se posicionem de maneira consciente e bem embasada na sociedade. Assim, parece razoável que as metodologias utilizadas nos diferentes níveis de escolaridade, incluindo o superior, busquem mais do que o ensino baseado na transmissão de conhecimento, focada na memorização. Certamente, reconhecemos a importância que tal processo apresenta na aprendizagem. No entanto, não podemos tê-lo como única meta, pois o acesso à informação é cada vez mais amplo. Torna-se relevante saber como dar sentido a tais informações e utilizá-las de forma adequada, visando, por exemplo, a resolver problemas reais e melhorar a qualidade de vida da população (BIZERRA \& URSI, 2014).

Anastasiou (2009) destaca o que define como operações de pensamento, que podem ser 
estimuladas pelos docentes do ensino superior ao escolherem e aplicarem uma diversidade de estratégias didáticas, propondo aos estudantes o exercício de processos mentais de complexidade variada e crescente, como: observação, comparação, interpretação, crítica, imaginação, aplicação de fatos e princípios a novas situações, decisão, planejamento de projetos e pesquisas, entre outros. Ainda, uma mesma estratégia, se bem conduzida, pode dar conta de estimular várias dessas operações (ANASTASIOU \& ALVES, 2009) e deve estar associada a processos de avaliação formativa, apesar das evidentes dificuldades para sua implementação (ROMANOWISK \& WACHOWICZ, 2009).

A forma como os docentes pensam e estruturam seus cursos/disciplinas, incluindo as escolhas de referenciais, estratégias, recursos e avaliações, pode perpetuar uma posição mais passiva do estudante ou promover uma ruptura, no sentido de efetivamente estimular sua autonomia. Guimarães (2003) aponta que a ideia da necessidade básica de autonomia está relacionada à motivação intrínseca. A autora destaca que os indivíduos são naturalmente propensos a realizar uma atividade por acreditarem que o fazem por vontade/desejo próprios e não apenas por obrigação, decorrente de demandas externas. Nessa perspectiva, agem de forma intencional com o objetivo de produzirem alguma mudança. Berbel (2011) indica uma série de estratégias de aprendizagem ativa que podem ser utilizadas para estimular a autonomia, como os projetos. Segundo a autora:

Entre as diversas contribuições aos alunos pela vivência do método de projetos, quando bem conduzido pelo(s) professor(es), podemos mencionar, a partir de Bordenave; Pereira (1982), os seguintes: proporcionar conteúdo vivo ao processo de aprendizagem; seguir o princípio da ação organizada em torno de objetivos; possibilitar a aprendizagem real, significativa, ativa, interessante, atrativa; concentrar na aprendizagem do aprendiz; desenvolver o pensamento divergente e despertar o desejo de conquista, iniciativa, investigação, criação e responsabilidade; levar os alunos a se inserirem conscientemente na vida social e/ou profissional. Podemos perceber, portanto, vários indicadores comuns entre os estudos voltados para a promoção da autonomia do aluno e o método ativo de projetos (BERBEL, 2011, p. 32).

O presente relato destina-se justamente a compartilhar as experiências vivenciadas em uma disciplina que busca promover a autonomia dos estudantes e, mais recentemente, optou por empreender tal desafio a partir da execução de projetos relacionados ao desenvolvimento, à aplicação e à avaliação de estratégias didáticas para o ensino de Ciências e Biologia. Visamos, desta forma, a promover maior interlocução sobre as práticas docentes, principalmente aquelas que almejam a autonomia do estudante de graduação.

\section{Desenvolvimento}

A disciplina atualmente intitulada Estratégias e Instrumentos Educacionais para o Ensino de Ciências e Biologia foi uma das primeiras a apresentar cunho pedagógico no Instituto de Biociências da USP. Ela teve início em 1998, com a denominação de Instrumentação para o Ensino de Ciências, e foi criada em decorrência de uma nova grade curricular iniciada em 1995 . O contexto do início da disciplina é apresentado por Brandimarte e Santos (2005), que indicam como um dos objetivos desenvolver no aluno a criatividade para a escolha, a elaboração e a adequação de instrumental para aulas de Ciências e de Biologia. Para tanto, os alunos criavam e aplicavam atividades práticas. Assim, evidencia-se que a disciplina sempre teve cunho prático.

Inicialmente, essa disciplina se caracterizava pela elaboração, por grupos de estudantes, de diversos instrumentos (três a quatro por semestre) para o Ensino Fundamental II, com temáticas focadas em conteúdos conceituais e escolhidas pela equipe docente. Após tal elaboração, realizavam-se aulas simuladas com os próprios estudantes de graduação e, finalmente, reflexões sobre o processo de elaboração-aplicação. As atividades eram documentadas sob a forma de roteiros, posteriormente 
disponibilizados na biblioteca do IB-USP. Alguns dos roteiros também foram disponibilizados na forma de CD e site ${ }^{1}$. A disciplina, ao longo da sua existência, foi oferecida tanto como optativa, quanto como obrigatória para os licenciandos do IB-USP, tendo número muito variável de participantes.

Com base no Programa de Formação de Professores da USP, mudanças foram empreendidas a partir de 2009. A disciplina tornou-se definitivamente optativa e novos professores, contratados especificamente para a área de Ensino, passaram a fazer parte da equipe docente. Primeiramente, buscamos focar as temáticas das estratégias não apenas em conteúdos conceituais, mas também em atitudinais e procedimentais. Em busca da maior autonomia dos estudantes, as temáticas passaram a ser escolhidas pelos próprios, em discussões mediadas pelos docentes. Também diminuímos o número de estratégias elaboradas, visando a dar maior espaço para as reflexões sobre as produções e adotando o formato de projeto para o desenvolvimento e a aplicação dessas estratégias. Incorporamos ainda aulas de subsídios à elaboração dos projetos. A princípio, os assuntos de tais aulas tinham caráter geral e eram escolhidos pela equipe docente (por exemplo: alfabetização científica, teorias da aprendizagem, modalidades didáticas).

Recentemente, experimentamos a elaboração de um cronograma aberto, no qual os estudantes tiveram liberdade para escolher a temática de suas estratégias e também das aulas de subsídio. Outra incorporação foi promover não apenas aulas simuladas, mas também estabelecer parcerias com instituições de ensino, inclusive não formais (o que sempre despertou grande interesse nos estudantes), nas quais pudessem efetivamente aplicar as estratégias propostas. A iniciativa de parcerias nos auxilia a abarcar os três pilares da Universidade: ensino, extensão e pesquisa, já inserindo os estudantes nessa perspectiva.

Em seu oferecimento de 2015, a disciplina contou com quarenta licenciandos no período noturno e doze no integral. Concentrou-se na elaboração de um único projeto em grupo (quatro a cinco estudantes) de elaboração-aplicação-avaliação de estratégia, com temática escolhida pelos próprios estudantes. Como exemplo de aulas propostas pela equipe docente e referendadas pelos alunos, tivemos "Introdução às Estratégias Didáticas" e "Feiras de Ciências como Estratégia para Promover a Alfabetização Científica". Além dessas aulas, os estudantes visitaram a Febrace (Feira Brasileira de Ciências e Engenharia), elaboraram um roteiro e entrevistaram participantes da feira, bem como compartilharam seus dados em discussão com toda a turma. Como exemplo de aula proposta pelos estudantes, tivemos o estudo de "Modelos Pedagógicos Alternativos". As docentes selecionaram textos sobre pedagogia Waldorf, escolas democráticas e educação disruptiva, que foram utilizados em um painel integrado sobre o tema. Outro exemplo foi a organização de uma mesa-redonda sobre "Inclusão e o Ensino de Ciências".

Quanto aos dez projetos desenvolvidos, as temáticas escolhidas pelos estudantes foram bastante variadas, assim como as estratégias didáticas adotadas para tratar de tais temáticas. Seis projetos ocorreram em espaços formais de ensino (creche ou escola), três em espaços de educação não formal (parque, museu ou centro cultural) e um constituiu-se em um aplicativo, porém voltado ao público escolar (Tabela 1, Figura 1). Chamam a atenção três projetos que envolveram Educação Infantil ou Ensino Fundamental I. Os estudantes relataram a importância de refletir e atuar não apenas em níveis de ensino para os quais serão habilitados (Fundamental II e Médio). A equipe docente considera importante ampliar os horizontes de atuação dos licenciandos, pois muitos poderão vir a trabalhar como laboratoristas, consultores ou mesmo formadores nesses outros níveis de ensino.

Adotamos o modelo de avaliação formativa (processual e continuada), baseada em três momentos de apresentação oral referentes ao projeto desenvolvido: (1) planejamento da estratégia a ser aplicada, (2) encaminhamento na instituição parceira e (3) aplicação/discussão final. E os estudantes entregaram, na forma escrita, um relato final, contendo informações valiosas e detalhadas sobre 


\section{Numeração e Título do projeto}

1. Desconstrução de estereótipos de gênero na Educação Infantil.

2. Formigando - Uma intervenção na Creche Oeste (USP).

3. Meio ambiente e pertencimento: descobrindo relações.

4. Sondagem de problemas ambientais e seus possíveis atenuantes na região urbana da cidade de São Paulo.

5. Percepção das diferenças de precisão do tato em alunos do GIEJA Butantã.

6. Composteira como instrumento de ensino na abordagem do conceito de cadeia alimentar.

7. Aplicação de jogo didático sobre a fotossíntese: Botânica - Sobreviva Se Puder!

8. Guia para o Museu Oceanográfico do IO-USP.

9. Crise hídrica: além da falta de chuvas.

10. Aprendendo imunologia pelo celular: o extraordinário laboratório da Dra. Agnes.
Tipo de instituição/meio em que a estratégia foi aplicada

Creche, Educação Infantil.

Creche, Educação Infantil.

Escola, Ensino Fundamental I.

Escola, Ensino Médio.

Escola, Educação de Jovens e Adultos.

Escola, Educação de Jovens e Adultos.

Centro Cultural Vergueiro, público espontâneo.

Museu do IO-USP, para público escolar.

Parque Villa Lobos, para público espontâneo.

Meio digital, para estudantes do Ensino Médio.

Tabela 1 - Projetos desenvolvidos pelos licenciandos durante a disciplina Estratégias e Instrumentos Educacionais para o Ensino de Ciências e Biologia (2015).

a experiência vivenciada, seguindo orientações explicitadas no roteiro fornecido pela equipe docente (Tabela 2). Também incorporamos algumas atividades realizadas durante as aulas de subsídio no processo de avaliação (por exemplo: relatos sobre entrevistas na Febrace).

Vale ressaltar que as produções desenvolvidas na disciplina ao longo dos anos, como roteiros de aula, videoaulas, audiovisuais, jogos, entre outros, têm sido publicadas em diferentes mídias, como sites, revistas científicas e de divulgação e ebooks, gerando publicações para os alunos (exemplos: MOLL \& LORENTI, 2014; URSI et al., 2012a, 2012b).

\section{Conclusões}

Avaliamos que as ideias e estratégias aqui relatadas, adotadas na disciplina Estratégias e Instrumentos Educacionais para o Ensino de Ciências e Biologia, têm promovido maior autonomia dos estudantes, o que gera grande motivação e entusiasmo para a maioria deles. Tal julgamento é baseado na postura dos estudantes e nos diálogos que estabelecemos ao longo de toda a disciplina, bem como nas reflexões empreendidas no momento de avaliação final do curso (realizada oralmente e aberta à participação de todos) e nos relatos de experiência apresentados na forma escrita. 


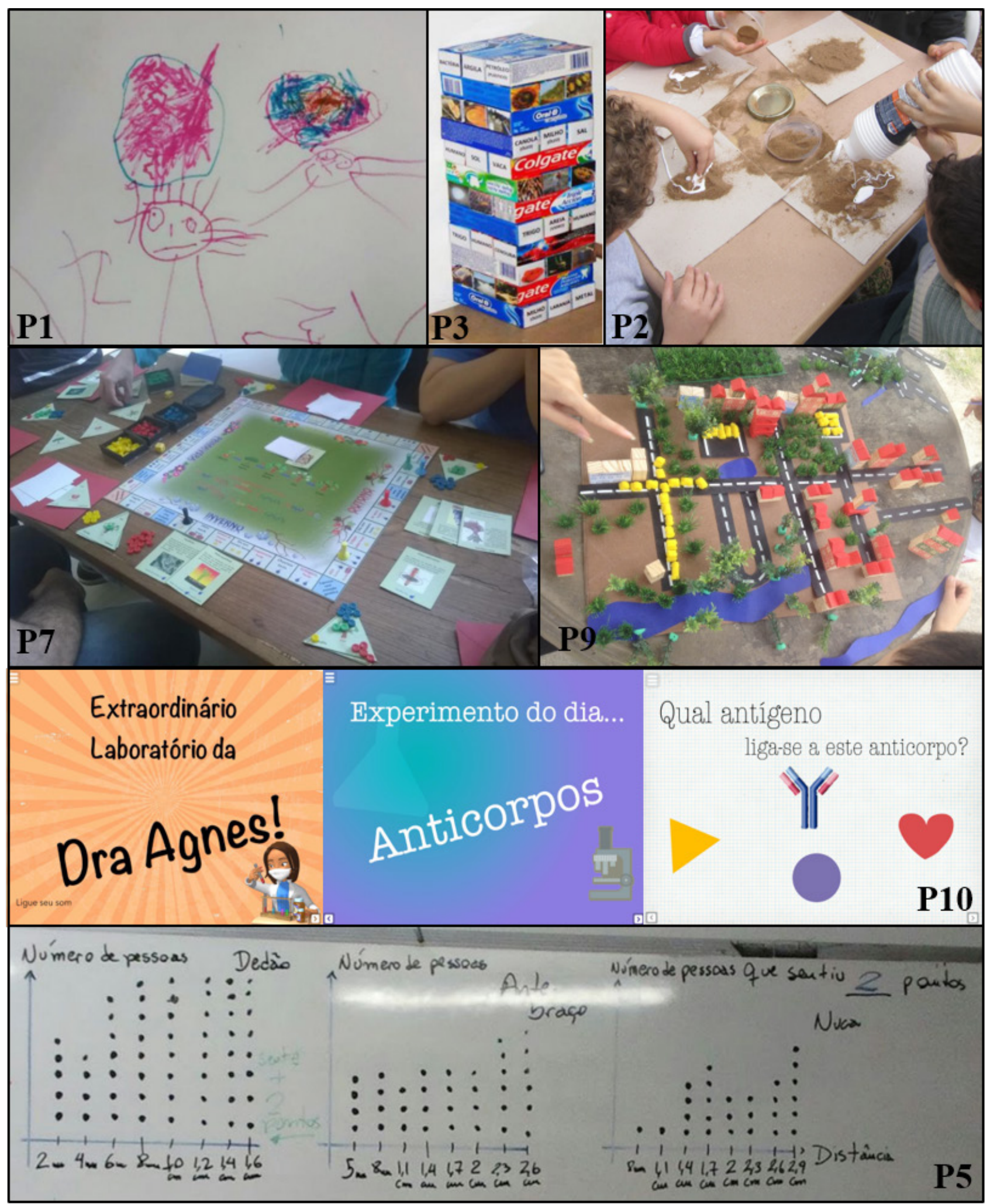

Figura 1 - Imagens ilustrativas (retiradas dos relatos escritos) de elementos referentes a alguns projetos (P) desenvolvidos durante a disciplina Estratégias e Instrumentos Educacionais para o Ensino de Ciências e Biologia (2015). P1: Desenho de estudante da creche representando uma atividade proposta por licenciandos, com bexigas rosas e azuis, visando a evidenciar que as brincadeiras não se tornavam mais ou menos divertidas em virtude da cor dos objetos e brinquedos. P3: "Jogo contra o desequilíbrio", elaborado por licenciandos. P2: Estudantes da creche construindo formigueiros. P7: Aplicação do jogo Botânica - Sobreviva Se Puder!, elaborado por licenciandos. P9: Realização de atividade na qual o público era convidado a montar uma maquete pensando sobre a questão hídrica e a urbanização. P10: Telas do aplicativo desenvolvido por licenciandos. P5: Gráficos de precisão tátil construídos coletivamente por licenciandos e estudantes da escola a partir de experimentos realizados. 


\section{Capa}

\section{Sumário}

\section{Resumo}

\section{Introdução e Justificativa}

- Apresentar a temática escolhida e sua relevância, bem como as motivações do grupo para desenvolvê-la.

- Abordar trabalhos de literatura que já foquem o ensino-aprendizagem de tal temática, com suas possibilidades e desafios.

- Contexto da intervenção.

- Público-alvo.

- Características gerais da instituição parceira.

- Processo de estabelecimento de parceria.

\section{Objetivos da intervenção}

- Conceituais, atitudinais e procedimentais.

\section{Descrição detalhada da intervenção}

- Com ações, tempo de duração, público-alvo efetivamente envolvido.

- Ilustrar e exemplificar com imagens, esquemas, tabelas etc.

\section{Reflexões}

- Avaliação das ações propostas em relação a aspectos como:

- impacto na formação dos integrantes, no público atendido, na instituição parceira;

- dificuldades encontradas ao longo do processo e formas de superação;

- destaque de principais pontos positivos de sua intervenção (que a tornam inovadora se comparada à forma mais tradicional de ensino);

- empenho e dedicação do grupo (autoavaliação).

\section{Comentários finais}

- Retomar os objetivos da intervenção, discutindo se e como foram alcançados.

- Propostas de mudanças a partir da aplicação da atividade com vistas a aprimorá-la.

- Outros aspectos que o grupo considerar relevantes.

Observação: É desejável que aspectos discutidos durante a apresentação oral final sejam incluídos neste relato.

Tabela 2 - Roteiro fornecido pela equipe docente aos licenciandos visando à elaboração, na forma escrita, de um relato final sobre a experiência vivenciada no desenvolvimento de projeto na disciplina Estratégias e Instrumentos Educacionais para o Ensino de Ciências e Biologia (2015).

Outro ponto de destaque se refere à relação universidade-sociedade. $\mathrm{O}$ valor da associação ensino-extensão já é reportado na literatura (e.g., THOMÉ et al., 2008) e pudemos corroborar tal tendência em nossa experiência junto à disciplina. Algumas parcerias têm se mantido por anos consecutivos, auxiliando tanto na formação inicial de nossos estudantes, como nas atividades das instituições parceiras. Pretendemos intensificar essa proposta de aproximação, sempre buscando uma relação dialogada e que supere a visão assistencialista de extensão.

Como desafios a serem superados, apontamos o número elevado de estudantes em algumas 
turmas, o que dificulta o atendimento mais personalizado necessário à estratégia que estamos adotando, e também a dificuldade de lidar com estudantes que encaram a licenciatura como uma "segunda opção" de carreira, chegando pouco estimulados para a disciplina, o que fica evidente já na abertura dela, quando realizamos um diálogo inicial sobre motivações e expectativas para o curso que se inicia.

\section{Nota}

1 Cf.: <http://www.ib.usp.br/iec/>.

\section{Referências Bibliográficas}

ANASTASIOU, L. G. C. "Ensinar, Aprender, Apreender e Processo de Ensinagem". In: ; ALVES, L. P. (orgs.). Processos de Ensinagem na Universidade: Pressupostos para as Estratégias de Trabalho em Aula. 8. ed. Joinville: Univille, 2009, pp. 15-44.

\& ALVES, L. P. "Estratégias de Ensinagem". In: _. \& _ . (orgs.). Processos de Ensinagem na Universidade: Pressupostos para as Estratégias de Trabalho em Aula. 8. ed. Joinville: Univille, 2009, pp. 73-108.

BERBEL, N. A. N. "As Metodologias Ativas e a Promoção da Autonomia de Estudantes". Semina: Ciências Sociais e Humanas, vol. 32, n. 1, pp. 25-40, 2011.

BIZERRA, A. F. \& URSI, S. Introdução aos Estudos da Educaşão I. Coord.: LOPES, S. G. \& VISCONTI, M.
A. São Paulo: Universidade de São Paulo/Universidade Virtual do Estado de São Paulo/Edusp, 2014.

BRANDIMARTE, A. L. \& SANTOS, D. Y. A. C. Instrumentação para o Ensino de Ciências. São Paulo: Instituto de Biociências da USP, 2005.

GUIMARÃES, S. E. R. Avaliação do Estilo Motivacional do Professor: Adaptação e Validação de um Instrumento. Tese (Doutorado em Educação), Faculdade de Educação, Universidade Estadual de Campinas, 2003.

MOLL, P. \& LORENTI, L. "Um Modelo Didático Tridimensional da Dupla Hélice do DNA". Genética na Escola, vol. 9, n. 1, pp. 38-45, 2014.

ROMANOWISK, J. P. \& WAGHOWICZ, L. A. "Avaliação Formativa no Ensino Superior: Que Resistências Manifestam os Professores e os Alunos". In: ANASTASIOU, L. G. C. \& ALVES, L. P. (orgs.). Processos de Ensinagem na Universidade: Pressupostos para as Estratégias de Trabalho em Aula. 8. ed. Joinville: Univille, 2009, pp. 132-150.

THOMÉ, A. C.; GONÇALVES, M. M. \& ZIMMER, A. "Incentivando a Realização de Projetos de Extensão Universitária durante as Aulas de Disciplinas Curriculares". Anais do XXVIII Congresso da Sociedade Brasileira de Computação, Belém, 2008.

URSI, S.; VISCONTI, M. A. \& BRANDIMARTE, A. L. Biodiversidade: Estratégias de Ensino para a Educação Básica. São Paulo: Instituto de Biociências, Universidade de São Paulo, 2012a.

; BIZERRA, A. F.; VISCONTI, M. A. Ambiente Marinho e Biodiversidade: Estratégias de Ensino para a Educação Básica. São Paulo: Instituto de Biociências, Universidade de São Paulo, 2012 b.

Publicado em 30/06/2017. 